NASA TECHNICAL NOTE

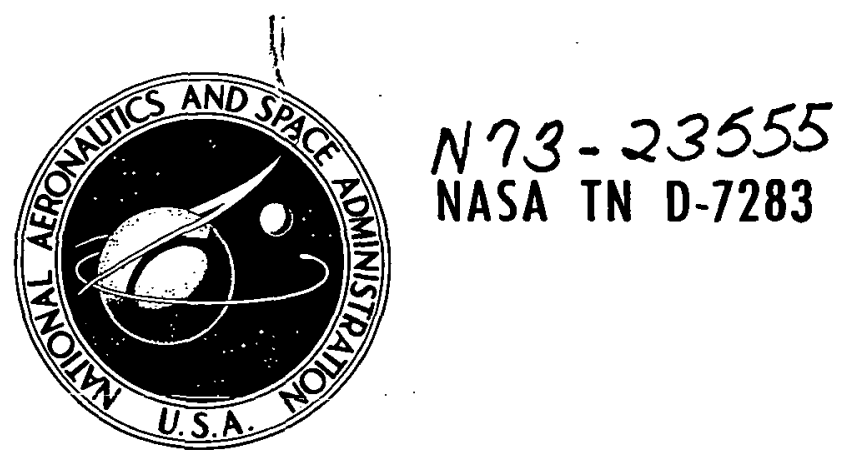

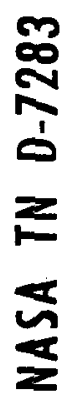

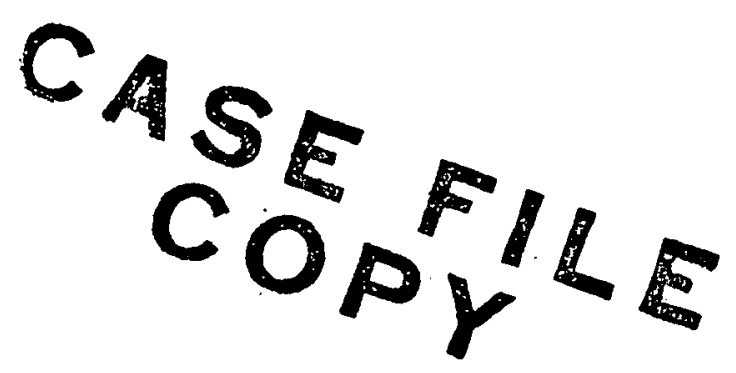

OXYGEN AND SULFUR INTERACTIONS

WITH A CLEAN IRON SURFACE

AND THE EFFECT OF RUBBING CONTACT

ON THESE INTERACTIONS

by Donald H. Buckley

Lewis Research Center

Cleveland, Obio 44135

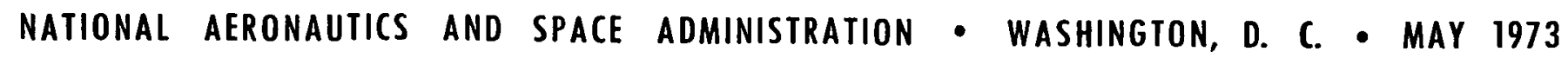




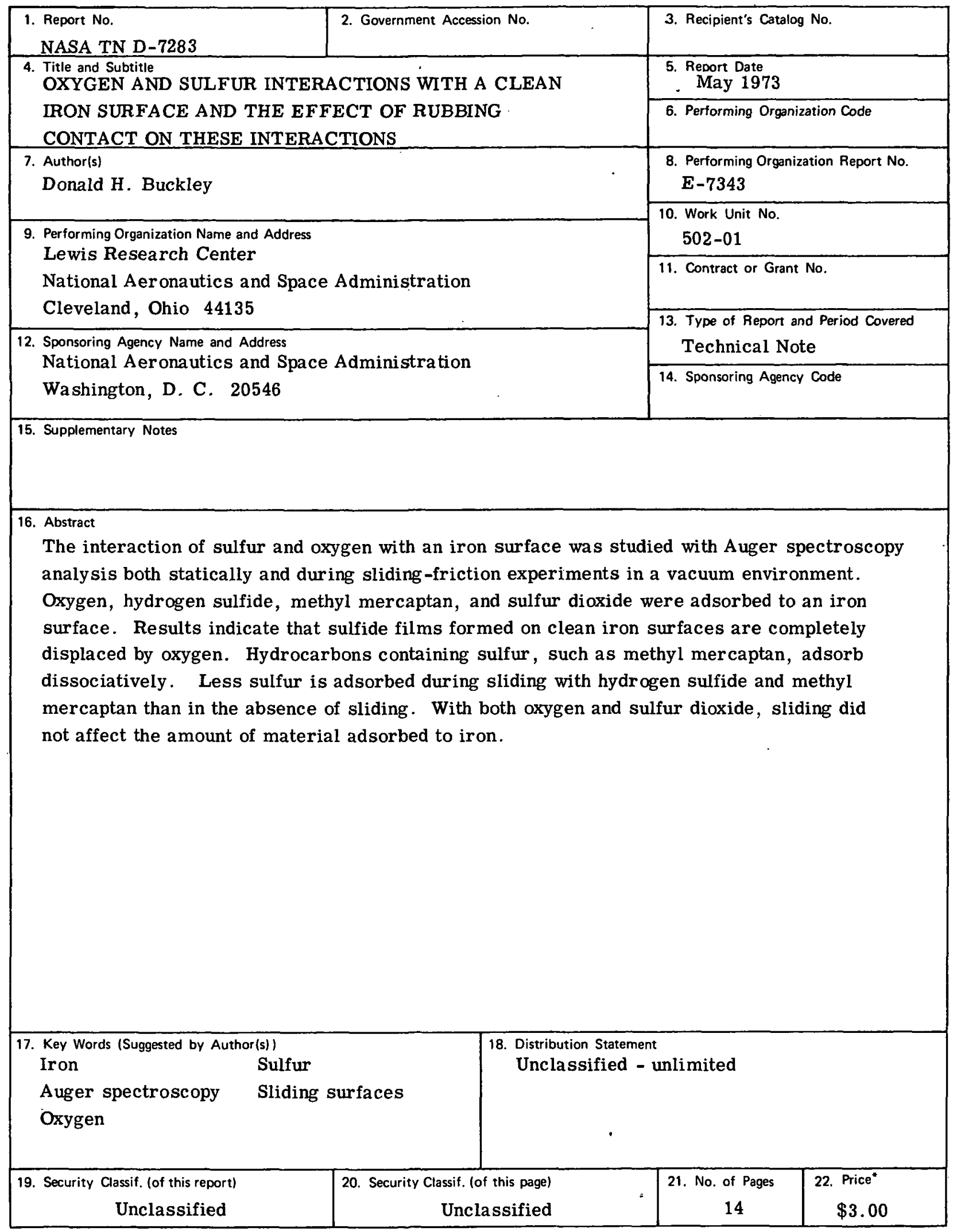

* For sale by the National Technical Information Service, Springfield, Virginia 22151 


\title{
OXYGEN AND SULFUR INTERACTIONS WITH A CLEAN IRON SURFACE AND THE EFFECT OF RUBBING CONTACT ON THESE INTERACTIONS
}

\author{
by Donald H. Buckley
}

Lewis Research Center

\section{SUMMARY}

An investigation was conducted to determine the nature of the chemical interactions of oxygen and sulfur with iron when surfaces are stationary and also during sliding in a vacuum environment. Various gases that contained sulfur, oxygen, or both were adsorbed to iron at $23^{\circ} \mathrm{C}$. The gases included axygen, hydrogen sulfide, methyl mercaptan, and sulfur dioxide. Friction experiments were conducted with a hemispherical rider sliding on a rotating disk. An Auger cylindrical mirror analyzer was used to monitor the iron surface chemistry.

The results of this study indicate that oxygen will completely displace sulfide films from iron surfaces. Hydrocarbons containing sulfur, such as methyl mercaptan, adsorb to an iron surface dissociatively. Only sulfur is detected on the iron surface. Sliding inhibits the formation of sulfide films on iron with the adsorption of hydrogen sulfide and methyl mercaptan. With oxygen and sulfur dioxide, the sliding process does not affect adsorption behavior.

\section{INTRODUCTION}

Sulfur is one of the most widely used elements in extreme-pressure lubricant additives. Despite its wide use, the exact mechanism of its interaction with metal surfaces in the presence of lubricants and normal environmental constituents (presence of air, water vapor, etc.) is still not clearly understood. Numerous works (e.g., refs. 1 to 8) have been published on the subject.

Some authors (refs. 2 to 5) have indicated that, with steel or iron surfaces, iron sulfide is formed and it is this compound which is responsible for the increased loadcarrying capacity. Other authors have found no evidence for the formation of iron sulfide but rather they have found iron oxides as the principal reaction products (refs. 1 
and 8). Still others have indicated that the exact mechanism is not known (ref. 7).

The real uncertainty appears to exist in whether the surface films are really sulfides or oxides. Other than reference 2, there is little or no evidence for the hydrocarbons interacting with the surface to form inorganic compounds (e.g., carbides).

The objective of this investigation was to examine the mechanism of interaction of sulfur and oxygen with a clean iron surface. The iron surface was exposed to axygen, hydrogen sulfide, methyl mercaptan, and sulfur diaxide. Further, sulfide-covered iron surfaces were exposed to oxygen, and oxide-covered surfaces to hydrogen sulfide. The objective here was to determine if substitution reactions occur at the surface. Formation of surface films was studied with an Auger cylindrical mirror analyzer, and interactions were examined for both the static case and when the surfaces were in sliding contact.

\section{MATERIALS}

The iron disk surfaces used in this investigation were fabricated from 99.99percent zone refined iron. The surfaces were polished on metallurgical papers down to 600 grit and were then polished with 3-micron-diamond paste to produce a mirror like surface.

All of the gases used were research grades. The oxygen contained $5 \mathrm{ppm}$ nitrogen, $16 \mathrm{ppm}$ argon, $8 \mathrm{ppm}$ krypton, and $9.4 \mathrm{ppm}$ methane. The hydrogen sulfide was 99.6 percent pure. The methyl mercaptan was 99.5 percent, and the sulfur dioxide was 99.98 percent pure.

\section{EXPERIMENTAL APPARATUS AND PROCEDURE}

\section{Specimens}

The friction-and-wear specimens consisted of a disk specimen 6.5 centimeters in diameter and 1.2 centimeters in thickness and a hemispherical rider with a 0.5 -centimeter radius. A schematic diagram of the specimens and the apparatus is shown in figure 1 . The disk specimen is mounted on a drive shaft which is rotated with a magnetic drive assembly. The drive assembly provides for rotation at various speeds (in this study, $30 \mathrm{~cm} / \mathrm{min}$ ). The rider specimen (aluminum oxide coated with a thin sputter deposited metal film $(1000 \AA))$ is mounted in a holder to one end of a stainlesssteel shaft. Sliding experiments are conducted with the rider specimen loaded against the iron disk surface. As the disk is rotated, the rider scribes a circular wear track 


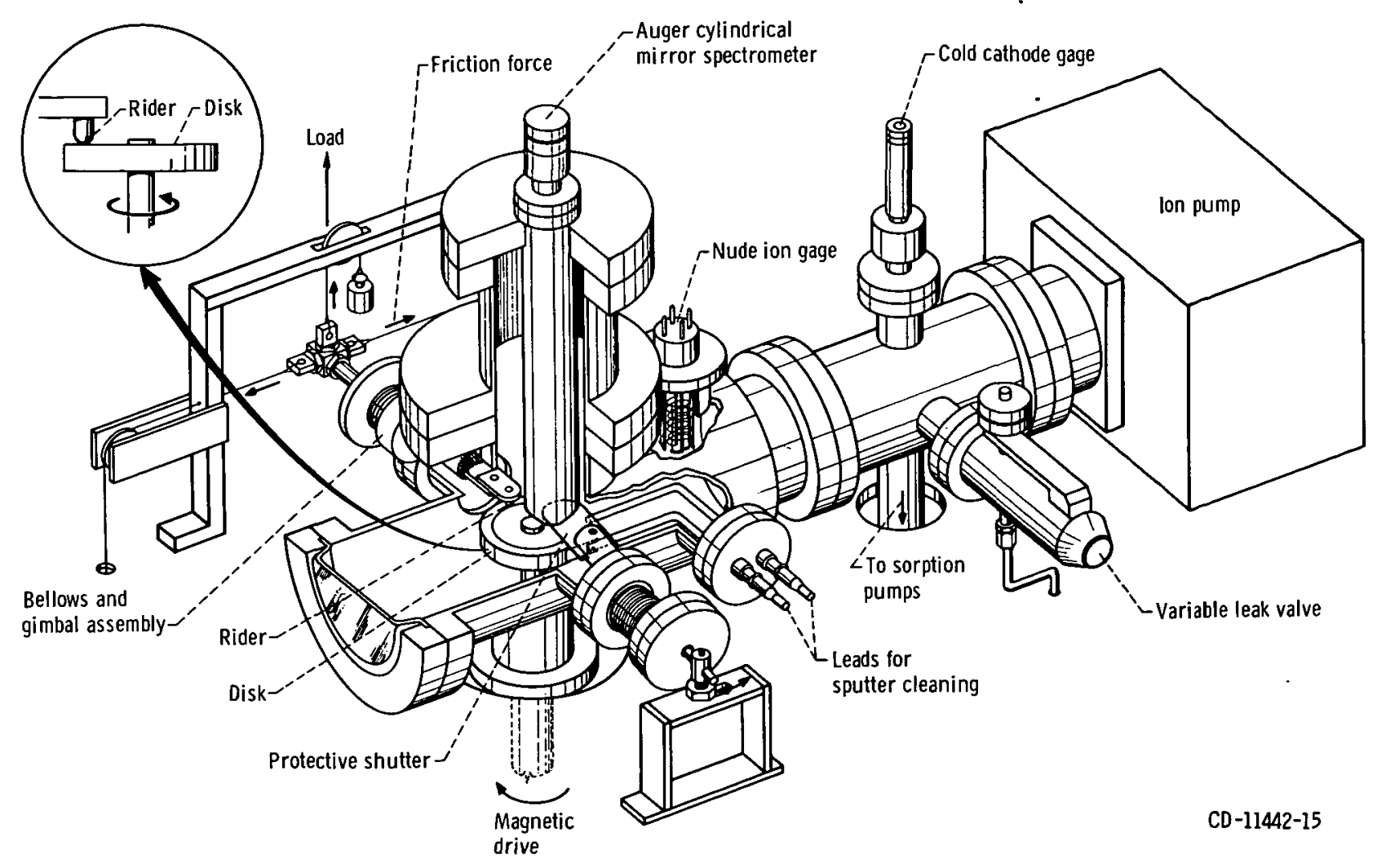

Figure 1. - Friction apparatus with Auger spectrometer.

on the flat surface of the disk. The load used in this investigation was 100 grams, and the temperature was $23^{\circ} \mathrm{C}$.

\section{Experimental Chamber}

The experiments are conducted in a vacuum chamber (see fig. 1). The vacuum system is pumped by sorption pumps and an ion pump Pressure in the vacuum system is read with a cold-cathode ionization gage. The vacuum system achieved a pressure of $1 \times 10^{-10}$ torr after bakeout at $250^{\circ} \mathrm{C}$.

\section{Measurements}

The friction force between the disk and rider specimen is continuously recorded during friction experiments. The beam which contains the rider specimen is welded into a bellows assembly which is gimbal mounted to the vacuum system. The gimbal 
mounting permits deadweight loading of the rider against the disk surface (fig. 1). At right angles to the deadweight loading, the beam containing the rider can move in two directions in the horizontal plane. Movement of the rider (with the disk as it rotates) is restrained by a cable which is attached to a beryllium-copper ring. The ring contains four sets of strain gages. These gages measure the frictional force between the disk and rider specimen. The friction force is recorded on a strip chart.

\section{Specimen Cleaning}

The specimens are cleaned by ion bombardment in the experimental chamber. The disk specimen is insulated from ground on the drive shaft. Two copper rods are brought to the disk from feed-throughs insulated from ground. The end of one rod terminates 0.5 centimeter from the circumferential edge of the disk specimen. This terminal establishes the positive potential in the glow discharge. The second rod has a berylliumcopper leaf attached to it. The end of the leaf opposite its attachment to the rod makes a "wiping" type of contact with the circumferential edge of the disk. The entire flat of the disk is cleaned by the sputtering as a result of being immersed in the glow discharge. At the same time, fresh iron is deposited on the aluminum oxide from the iron disk as a result of the sputtering process. The specimens are ion-bombarded by bleeding research-grade argon gas into the system until a pressure of about 0.02 torr is achieved. A direct-current power supply is used to supply 1000 volts between the disk and the floating electrode. With the negative potential on the disk, positively charged argon ions bombard and sputter clean the specimen surfaces.

\section{Auger Analysis}

Elemental analysis of the disk specimen surface can be made before, during, and after the friction-and-wear experiment by using an Auger cylindrical mirror analyzer with an integral electron gun. The point of contact of the rider with the disk passes under the Auger beam 20 seconds after the disk moves out of the contact zone. This time element can be changed by changing the speed at which the disk rotates. The disk could rotate over a broad range of speed, and Auger analysis could still be performed. The Auger analyzer is a commercial unit, the essential elements of which are described in the literature (ref. 9).

The primary beam of electron is directed at the disk surface by a beam from the electron gun in the Auger cylindrical mirror analyzer. The beam is focused on the wear track scribed by the rider in sliding contact with the disk. The beam contact is $150^{\circ}$ 
away from the rider on the disk surface. The beam spot diameter is 0.2 millimeter. The gun contains deflection plates which allow positioning of the beam on the disk surface.

The secondary electrons come off the specimen surface, pass through the Auger can, then pass through to an energy analyzer. They are collected by the electron multiplier. Elemental identification is accomplished by detection of the Auger electron energies. The Auger electrons that appear in the secondary -electron distribution "fingerprint" the surface elements to a depth of approximately four atomic layers.

Auger traces are displayed on an oscilloscope. The sweep control module permits a full spectrum scan for those elements of interest in friction, wear, and lubrication in 0.10 second. Thus, there exists the capability of monitoring a moving or rotating surface and detecting dynamic variations in surface chemistry.

\section{RESULTS AND DISCUSSION}

\section{Oxygen}

A sputter-cleaned iron disk surface was exposed to various amounts of oxygen. Exposures are measured in langmuirs ( 1 langmuir $=10^{-6}$ torr $-\mathrm{sec}$ ). The disk was exposed to oxygen while stationary and during a sliding friction experiment. The results, shown in figure 2, indicate that the iron surface continued to adsorb oxygen in a linear manner with increase in exposure. The relative amount of oxygen adsorbed by the surface was insensitive to the sliding process. Both static adsorption and adsorption during sliding produced the same results.

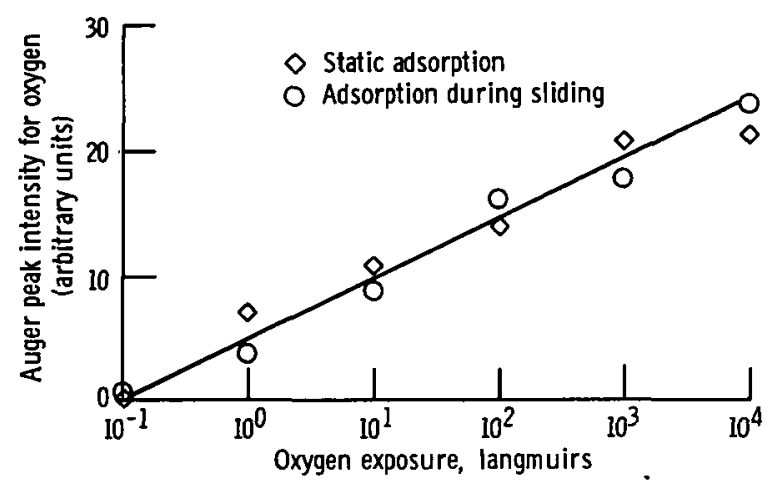

Figure 2. - Auger spectroscopy detection of oxygen adsorbed on a clean iron surface exposed to oxygen under static conditions and during sliding friction. Sliding velocity, 30 centimeters per minute; load, 100 grams; ambient temperature, $23^{\circ} \mathrm{C}$. 


\section{Hydrogen Sulfide}

A clean iron surface was exposed to hydrogen sulfide. Auger spectra are presented in figure 3 for the clean iron surface and that same surface after exposure to 10000 langmuirs of hydrogen sulfide. In figure 3(a), the only Auger peaks are the four associated with the clean iron. After exposure to hydrogen sulfide (fig. 3(b)), there is a large sulfur peak due to the adsorption of hydrogen sulfide to the surface.

Hydrogen sulfide adsorbs to iron dissociatively (refs. 10 and 11). Only sulfur remains on the surface after adsorption. This is the case with iron as well as with other metals, such as copper.

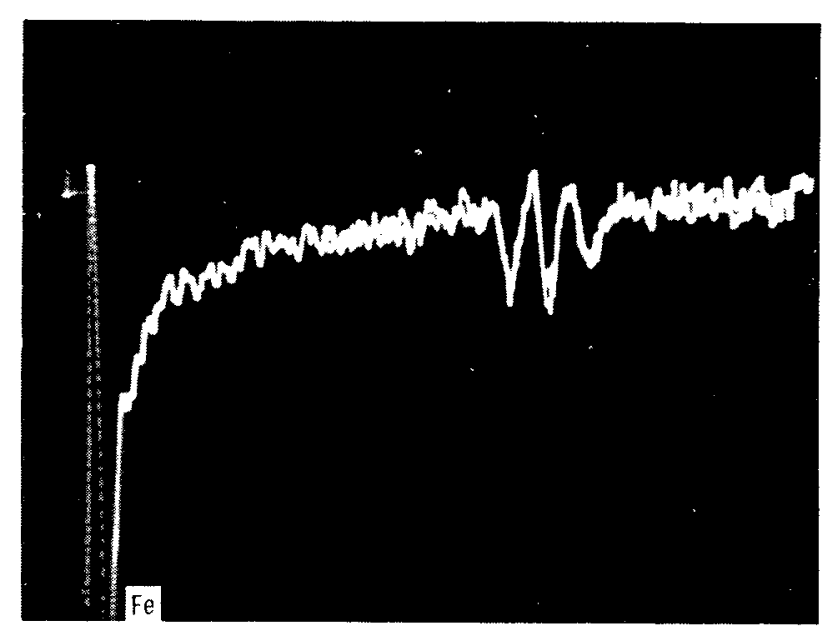

(a) Clean iron surface.

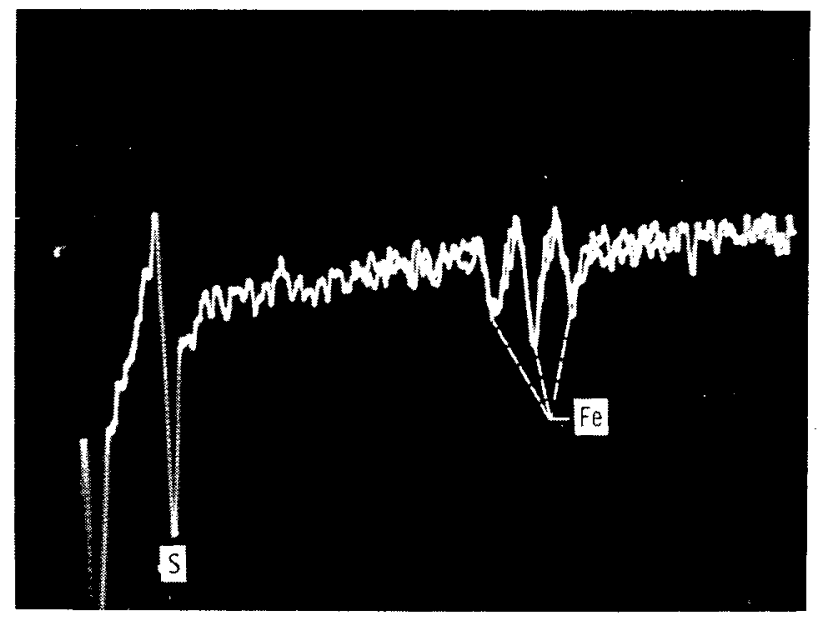

(b) Iron surface after exposure to hydrogen sulfide.

Figure 3. - Auger spectra of an iron surface before and after exposure to 10000 langmuirs of hydrogen sulfide at $23^{\circ} \mathrm{C}$.

Experiments were conducted with iron exposed to hydrogen sulfide in both static adsorption studies and during sliding friction experiments. The results obtained are presented in figure 4. Unlike the results obtained with oxygen (fig. 2), the results obtained with hydrogen sulfide are influenced by sliding. At exposures bey ond 10 langmuirs, less sulfur is present on the sliding surface. Sliding either inhibits adsorption or induces desorption once adsorption has occurred. With sliding, the frictional heating at the interface can contribute to such desorption. 


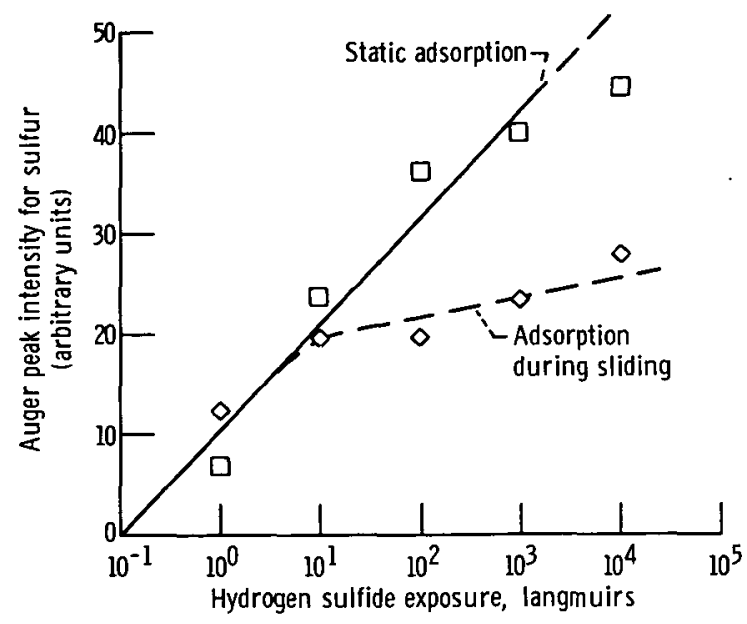

Figure 4. - Auger spectroscopy detection of sulfur adsorbed on a clean iron surface exposed to hydrogen sulfide under static conditions and during sliding friction. Sliding velocity, 30 centimeters per minute; load, 100 grams; ambient temperature, $23^{\circ} \mathrm{C}$.

The sulfide films generated on the iron surface were relatively stable. Heating the iron to $250^{\circ} \mathrm{C}$ for 12 hours did not result in desorption of the sulfur. The sulfur Auger peak after heating had not been diminished in size by the prolonged heating.

\section{Oxygen Displacement of Sulfur}

In practical lubrication systems, oxygen is nearly always present in the environment. It is of interest, therefore, to know what effect oxygen has on sulfide films such as those evidenced by the data of figure 4 . The sulfide films of figure 4 were, therefore, subjected to various exposures of oxygen. Figure 5 presents Auger spectra after two different exposures of oxygen.

The spectrum of figure 5(a) indicates the presence of both sulfur and oxygen at 100 langmuirs of oxygen. After a total exposure of 10000 langmuirs of oxygen, the Auger spectrum of figure 5 (b) was obtained. This indicates, in addition to iron, only oxygen peaks. The sulfur is absent. Thus, there has been a total displacement of sulfur from the iron surface by the oxygen.

The change in both the sulfur and oxygen peak intensities with oxygen exposure can be seen in figure 6 . The sulfur peak continues to decrease in intensity with oxygen exposure, while oxygen concentration on the surface continues to increase. At 10000 langmuirs, the sulfur has completely disappeared.

If the oxygen Auger peak intensities of figure 2 are compared with those of figure 6 , as is done in figure 7 , it becomes apparent that oxygen adsorption is retarded some- 


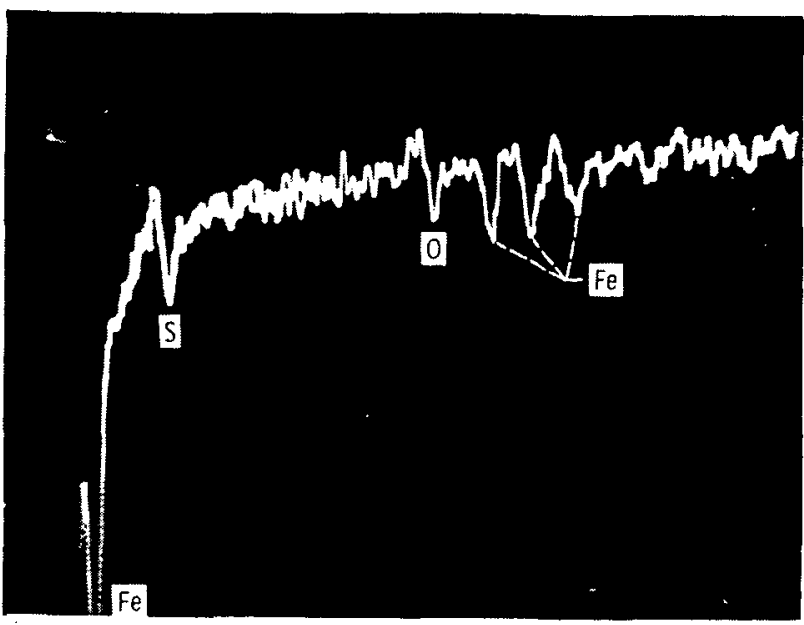

(a) Film exposed to 100 langmuirs of oxygen.

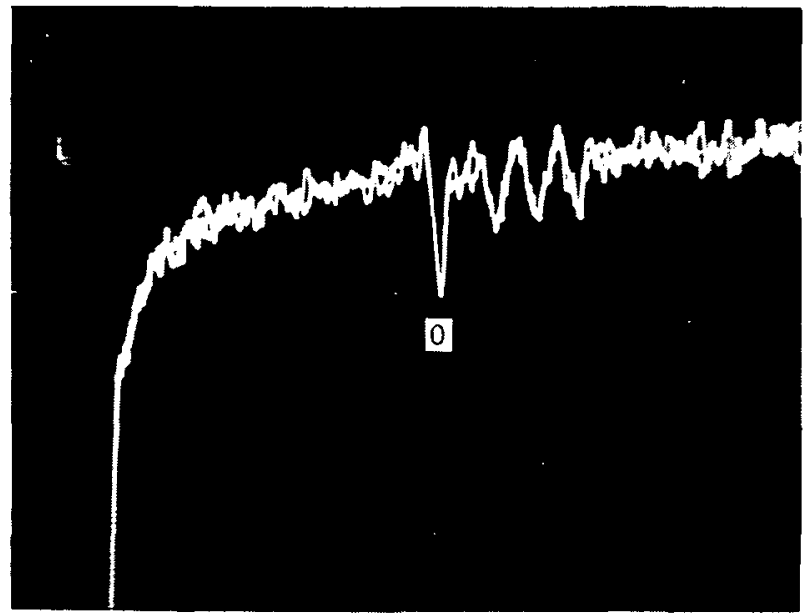

(b) Film exposed to 10000 langmuirs of oxygen.

Figure 5. - Auger spectra for the displacement of a sulfide film from an iron surface by oxygen at $23^{\circ} \mathrm{C}$.

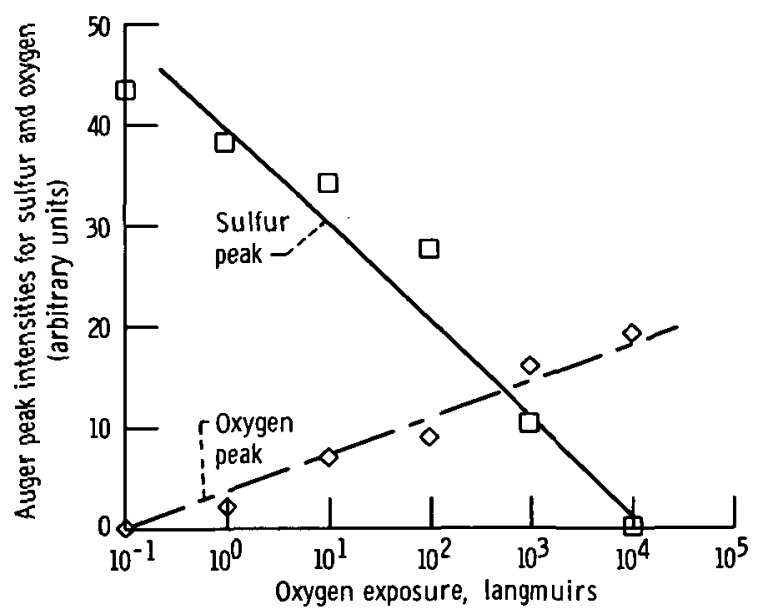

Figure 6. - Auger spectroscopy evidence for the displacement of sulfur from an iron surface by oxygen. Initial sulfide film formed by exposure of iron surface to 10000 langmuirs of hydrogen sulfide at $23^{\circ} \mathrm{C}$.

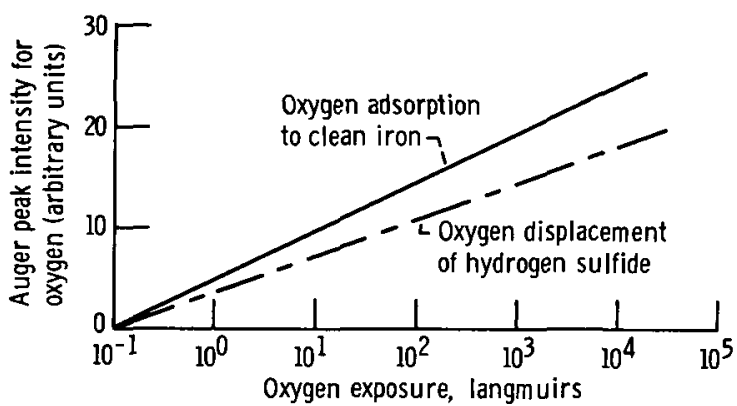

Figure 7. - Auger peak intensities for the adsorption of oxygen to clean iron and for the displacement of a hydrogen sulfide film from iron by oxygen at $3^{\circ} \mathrm{C}$.

what by the presence of the sulfide film. The kinetics of the substitution reaction are slower than direct oxidation of iron.

In a different set of experiments, hydrogen sulfide was adsorbed to an oxygencovered iron surface. The object was to determine if hydrogen sulfide chemisorbed to oxygen. The Auger emission spectroscopy results obtained are present in figure 8. The sulfur peak in figure $8(a)$ increases in intensity with hydrogen sulfide exposure. The oxygen peak decreases as it is covered over by the sulfur. The results of figure 8(a), then, indicate that hydrogen sulfide will chemisorb to oxygen present on an iron surface. Physical adsorption does not occur under the conditions of these experiments. 


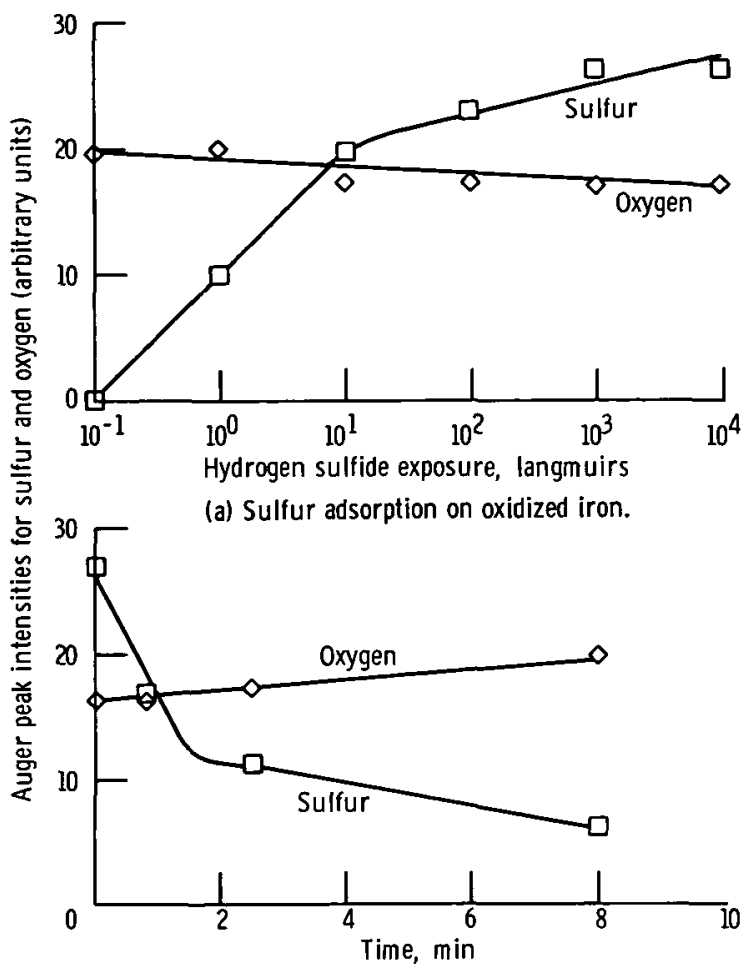

(b) Electron induced desorption of hydrogen sulfide.

Figure 8. - Auger spectroscopy sulfur peak intensities for the adsorption of hydrogen sulfide on an oxide covered iron surface at $23^{\circ} \mathrm{C}$ and electron induced desorption of hydrogen sulfide.

The hydrogen sulfide present on the surface is subject to electron-induced desorption. That is, the electron energy associated with the Auger primary electron beam is sufficient to desorb the adsorbed species. Evidence for this is presented in the curves of figure $8(\mathrm{~b})$. The sulfur peak intensity at a fixed spot on the surface decreases with time, while the oxygen peak increases slightly. The oxygen peak increases in intensity because the oxygen is being exposed as the sulfur is removed.

\section{Methyl Mercaptan}

Sulfur, when present in a lubricant as an extreme-pressure additive is usually formulated with the lubricant in the form of an organic compound. A question to be resolved is how the sulfur is liberated from the organic molecule. Adsorption studies were, therefore, conducted with the hydrocarbon methyl mercaptan $\left(\mathrm{CH}_{3} \mathrm{SH}\right)$. Results for both static adsorption and adsorption during sliding are presented in figure 9 .

In figure 9, the Auger peak intensity for sulfur is plotted as function of exposure to methyl mercaptan for both the static and the dynamic, or sliding, experiments. As with 


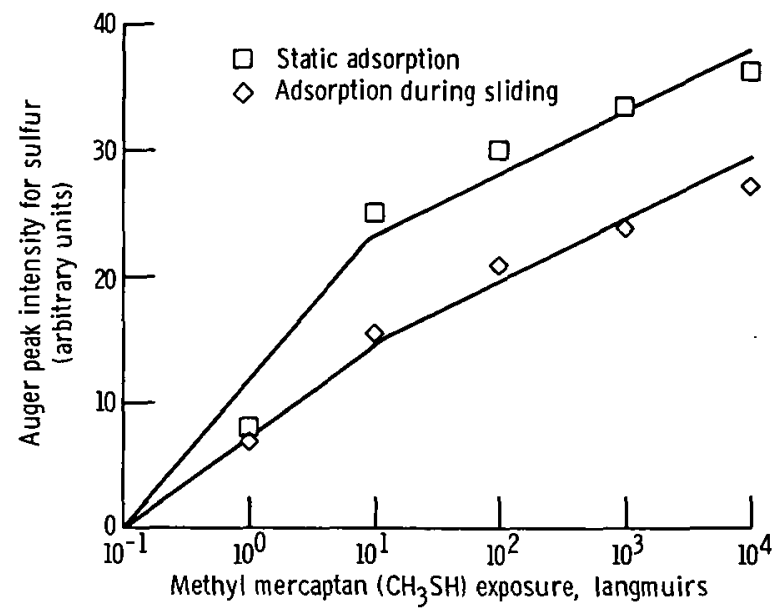

Figure 9. - Auger spectroscopy detection of sulfur adsorbed on a clean iron surface exposed to methyl mercaptan under static conditions and during sliding friction. Sliding velocity, 30 centimeters per minute; load, 100 grams; ambient temperature, $2^{\circ} \mathrm{C}$.

hydrogen sulfide, the amount of sulfur adsorbed during sliding was less than with static adsorption.

The interesting aspect of methyl mercaptan adsorption to iron is that there was no evidence of carbon on the surface with adsorption. A quadrupole mass spectrometer was mounted on the vacuum system to monitor the composition of the gases in the environment and the principal $\mathrm{M} / \mathrm{e}$ mass-to-charge ratios ( $\mathrm{M} / \mathrm{e})$ were 48, 47, 16 , and 15 . These $M / e$ values were detected with adsorption of the methyl mercaptan. The $M / e$ value of 48 is the methyl mercaptan, the 47 value is that molecule which lacks a hydrogen atom.

The $\mathrm{M} / \mathrm{e}$ values of 15 and 16 are $\mathrm{CH}_{3}^{+}$and $\mathrm{CH}_{4}$, respectively. The se originate from adsorptive dissociation of the methyl mercaptan, with sulfur adsorbing on the iron, and the methyl group passing into the vacuum system. Methane $\left(\mathrm{CH}_{4}\right)$ in all probability results from combination of the methyl group with hydrogen present in the vacuum system.

The complete absence of carbon on the iron surface even at exposures to 10000 langmuirs of methyl mercaptan indicates that there is total dissociation of the hydrocarbon molecule. Thus, only the active sulfur in organic molecules such as methyl mercaptan remains on clean iron surfaces after adsorptive interactions. A similar observation was made in reference 12 with semiconductors.

The sulfur covered iron surface originating from the methyl mercaptan was exposed to oxygen, just as the hydrogen sulfide developed sulfur film had been. Again, the sulfur film was completely displaced from the iron surface by oxygen. Auger analysis after exposure to 10000 langmuirs of oxygen revealed only iron and oxygen peaks. 


\section{Sulfur Dioxide}

Since oxygen displaces sulfur from an iron surface, experiments were conducted in which both oxygen and sulfur were present in the same molecule. Sulfur dioxide $\left(\mathrm{SO}_{2}\right)$ was chemisorbed to a clean iron surface both statically and during sliding. The results obtained are indicated in the Auger spectrometer results of figure 10.

In figure 10 , both the oxygen and the sulfur were detected on the surface with exposures of as little as 1 langmuir. These results indicate that adsorption is molecular. If dissociative adsorption occurred, sulfur might not have been detected.

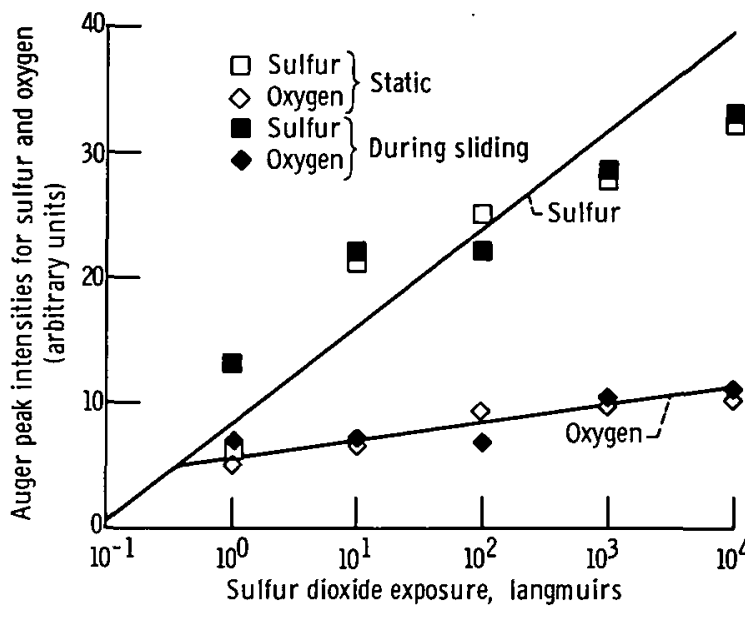

Figure 10. - Auger spectroscopy detection of sulfur and oxygen adsorbed on a clean iron surface exposed to sulfur dioxide under static conditions and during sliding friction. Sliding velocity, 30 centimeters per minute; load, 100 grams; ambient temperature, $2^{\circ} \mathrm{C}$.

The data of figure 10 indicate that sliding exerts no influence on adsorption. The sulfur and oxygen data points follow the same curves. In both cases, surface uptake of sulfur dioxide increases with increasing exposure.

\section{CONCLUSIONS}

Based on the experimental results obtained in this investigation at $23^{\circ} \mathrm{C}$ with oxy gen, hydrogen sulfide, methyl mercaptan, and sulfur dioxide adsorbed to iron, the following conclusions are drawn:

1. Sulfide films present on iron surfaces are displaced by oxygen. 
2. Hydrocarbons such as methyl mercaptan adsorb to iron dissociatively. Only sulfur remains on the iron surface. The hydrocarbon radical passes into the sys tem.

3. The sliding process inhibits the adsorption of hydrogen sulfide and methyl mer captan to an iron surface.

4. Sliding exerts no effect on the adsorption of oxygen and sulfur dioxide to an iron surface.

5. Sulfur dioxide adsorbs to an iron surface molecularly.

\section{Lewis Research Center,}

National Aeronautics and Space Administration,

Cleveland, Ohio, March 7, 1973,

502-01.

\section{REFERENCES}

1. Simard, G. L.; Russel, H. W.; and Nelson, H. R.: Extreme Pressure Lubricants. Ind. Eng. Chem., vol. 33, no. 11, Nov. 1941, pp. 1352-1359.

2. Vinogradov, G. V.; and Morozova, O, E.: A Study of the Wear of Steel Under Heavy Loads with Lubricants Containing Sulphur-Based Additives. Wear, vol. 3, 1960, pp. 297-308.

3. Dorinson, A.; and Broman, V. E.: Extreme Pressure Lubrication and Wear. The Chemical Reactivity and the Extreme Pressure Action of Two Aliphatic Dilsulfides. ASLE Trans., vol. 5, no. 1, Apr, 1962, pp. 75-90.

4. Sakurai, Toshio; Ikeda, Sakuji; and Okabe, Heihachiro: A Kinetic Study on the Reaction of Labeled Sulfur Compounds with Steel Surfaces During Boundary Lubrication. ASLE Trans., vol. 8, no. 1, Jan. 1965, pp. 39-47.

5. Sakurai, Toshio; Ikeda, Sakuji; and Okabe, Heihachiro: The Mechanism of Reaction of Sulfur Compounds with Steel Surface During Boundary Lubrication, Using $\mathrm{S}^{35}$ as a Tracer. ASLE Trans., vol. 5, no. 1, Apr. 1962, pp. 67-74.

6. Sakurai, Toshio; and Sato, Kachio: Study of Corrosivity and Correlation Between Chemical Reactivity and Load-Carrying Capacity of Oils Containing Extreme Pressure Agents. ASLE Trans., vol. 9, no. 1, Jan. 1966, pp. 77-87.

7. Rowe, Carleton N.; and Dickert, Joseph J., Jr.: The Relation of Antiwear Function to Thermal Stability and Structure for Metal 0,0 - Dialkylphosphorodithioates. ASLE Trans., vol. 10, no. 1, Jan. 1967, pp. 85-90. 
8. Godfrey, Douglas: Chemical Changes in Steel Surfaces During Extreme Pressure Lubrication. ASLE Trans., vol. 5, no. 1, Apr. 1962, pp. 57-66.

9. Chang, Chuan C.: Auger Electron Spectroscopy, Surface Sci., vol. 25, 1971, pp. 53-79.

10. Domange, J. L.; and Oudar, J.: Conditions of Formation, Structure, and Stability of Adsorbed Sulfur Layers on Copper. Surface Phenomena of Metals. Monograph No. 28, Society of Chemical Industry, 1968.

11. Domange, J. L.; Oudar, J.; and Benard, J.: Growth Mechanism and Structure of Adsorption Layers. Molecular Processes on Solid Surfaces. McGraw-Hill Book Co., Inc. , 1968.

12. Meyer, F.; and Vrakking, J. J.: Quantitative Aspects of Auger Election Spectroscopy. Surface Sci., vol. 33, 1972; pp. 271-294. 
"The aeronautical and space activities of the United States shall be conducted so as to contribute. . . to the expansion of buman knowledge of phenomena in the atmosphere and space. The Administration shall provide for the widest practicable and appropriate dissemination of information concerning its activities and the results thereof."

-National Aeronautics and Space ACt of 1958

\section{NASA SCIENTIFIC AND TECHNICAL PUBLICATIONS}

TECHNICAL REPORTS: Scientific and technical information considered important, complete, and a lasting contribution to existing knowledge.

TECHNICAL NOTES: Information less broad in scope but nevertheless of importance as a contribution to existing knowledge.

TECHNICAL MEMORANDUMS:

Information receiving limited distribution because of preliminary data, security classification, or other reasons. Also includes conference proceedings with either limited or unlimited distribution.

CONTRACTOR REPORTS: Scientific and technical information generated under a NASA contract or grant and considered an important contribution to existing knowledge.
TECHNICAL TRANSLATIONS: Information published in a foreign language considered to merit NASA distribution in English.

SPECIAL PUBLICATIONS: Information derived from or of value to NASA activities. Publications include final reports of major projects, monographs, data compilations, handbooks, sourcebooks, and special bibliographies.

\section{TECHNOLOGY UTILIZATION}

PUBLICATIONS: Information on technology used by NASA that may be of particular interest in commercial and other non-aerospace applications. Publications include Tech Briefs, Technology Utilization Reports and Technology Surveys.

Defails on the availability of these publications may be obtained from:

\section{SCIENTIFIC AND TECHNICAL INFORMATION OFFICE}

\section{NATIONAL AERONAUTICS AND SPACE ADMINISTRATION Washington, D.C. 20546}

